ADMA in the airways occur in acute exacerbations. It will be very interesting to see what future studies comparing the utility of biomarkers between different compartments will tell us about the role of ADMA in asthma.

0 @ERSpublications

Sputum ADMA increases in mild allergic asthmatics after allergen challenge, concomitant with onset of airways obstruction http://ow.ly/nM3VV

Jeremy A. Scott ${ }^{1,2}$, Gail M. Gauvreau ${ }^{3}$ and Hartmut Grasemann ${ }^{4}$

${ }^{1}$ Dept of Health Sciences, Lakehead University, Thunder Bay, ON, ${ }^{2}$ Division of Medical Science, Northern Ontario School of Medicine, Thunder Bay and Sudbury, ON, ${ }^{3}$ Division of Respirology, Dept of Medicine, McMaster University, Hamilton, ON, and ${ }^{4}$ Program in Physiology and Experimental Medicine, Research Institute, and Division of Respiratory Medicine, Dept of Paediatrics, University of Toronto, Toronto, ON, Canada.

Correspondence: J.A. Scott, Dept of Health Sciences, Lakehead University, 955 Oliver Road, Thunder Bay, ON, P7B 5E1, Canada. E-mail: jascott1@lakeheadu.ca

Received: May 082013 | Accepted after revision: May 172013

Conflict of interest: None declared.

\title{
References
}

Lau EMT, Morgan PE, Belousova EG, et al. Asymmetric dimethylarginine and asthma: results from the Childhood Asthma Prevention Study. Eur Respir J 2013; 41: 1234-1237.

2 Scott JA, North ML, Rafii M, et al. Asymmetric dimethylarginine is increased in asthma. Am J Respir Crit Care Med 2011; 184: 779-785.

3 Carraro S, Giordano G, Piacentini G, et al. Asymmetric dimethylarginine in exhaled breath condensate and serum of children with asthma. Chest 2013; 144: 405-410.

4 Holguin F, Comhair SA, Hazen SL, et al. An association between L-arginine/asymmetric dimethyl arginine balance, obesity, and the age of asthma onset phenotype. Am J Respir Crit Care Med 2013; 187: 153-159.

5 Lara A, Khatri SB, Wang Z, et al. Alterations of the arginine metabolome in asthma. Am J Respir Crit Care Med 2008; 178: 673-681.

6 Boulet LP, Gauvreau G, Boulay ME, et al. The allergen bronchoprovocation model: an important tool for the investigation of new asthma anti-inflammatory therapies. Allergy 2007; 62: 1101-1110.

7 Pizzichini E, Pizzichini MM, Efthimiadis A, et al. Indices of airway inflammation in induced sputum: reproducibility and validity of cell and fluid-phase measurements. Am J Respir Crit Care Med 1996; 154: 308-317.

\section{Early-life wheeze: "the Child is father of the Man"}

To the Editor:

We applaud the recent article by HovLAND et al. [1] from the Environment and Childhood Asthma (ECA) study, which provides intriguing insight into the longer-term consequences of early-life wheezing. Employing a different classification of early wheeze (recurrent bronchial obstruction (RBO)) to previous studies, including our own Isle of Wight Birth Cohort (IOWBC), their findings suggest that a notinsubstantial proportion of such disease is associated with wheezing at the end of childhood. We note their comparison of findings with those reported from the 10-year follow-up of our IOWBC, highlighting both similarities and differences between the two studies. They also query what a later follow-up of the IOWBC would show in relation to young adult outcome of early-life wheezing. The ECA report followed up patients at 16 years of age, whereas the corresponding follow-up of our cohort was at 18 years. Using data from that follow-up, we can both corroborate the findings of HovLand et al. [1] and shed further light on their understanding by returning to our earlier classification of wheeze phenotypes in the first decade of life.

Hovland et al. [1] used a very stringent definition of "early life" confined to wheezing events in the first 2 years of life. By contrast, the IOWBC papers they compare their findings against use a broader definition of "early life" encompassing the first 4 years of life [2,3]. Interest is growing in the influence of early life as a period of vulnerability for disease development and an argument could be made that the approach of Hovland et al. [1] better captures that period. With a wider timespan, we previously found prevalence for early life (in the first 4 years) wheezing of $40 \%$ at 10 years in our cohort [2]. We also showed that $37 \%$ of 
such early-life wheezing was still evident at 10 years as a persistent wheeze phenotype [4] associated with greater airflow limitation, bronchial hyperresponsiveness (BHR), morbidity [2] and risk of asthma death [5]. The remainder of the early-life wheezers were defined as early transient wheeze. If we retain a definition of 4 years for early life (rather than 2 years as in the ECA) and designate wheezing (rather than asthma) in that period as RBO, how do RBO outcomes at 18 years in the IOWBC compare to the ECA outcomes at 16 years?

In the IOWBC, $32.2 \%$ of patients with RBO had current wheeze (in the past 12 months) at 18 years, which is less than that reported for the ECA at 16 years, when wheeze-based interpretation was used in that study. However, in the IOWBC, $28.8 \%$ of those with RBO had current asthma (definition) at 18 years, which parallels the ECA findings at 16 years. In our study, comparing 18-year-old current wheezers with and without a history of RBO, those with RBO had significantly higher prevalence of current asthma $(83.0 \%$ versus $69.1 \%, \mathrm{p}=0.019$; OR $2.18,95 \% \mathrm{CI} 1.13-4.23)$ and current smoking status $(42.3 \%$ versus $26.9 \%$, $\mathrm{p}=0.020$; OR 1.99, 95\% CI 1.11-3.58). RBO subjects also had significantly lower forced expiratory volume in $1 \mathrm{~s}$ /forced vital capacity ratio $(0.83$ versus $0.86, \mathrm{p}=0.02)$. The groups did not differ by sex, atopic status, allergic comorbidity, BHR or exhaled nitric oxide fraction ( $\mathrm{FeNO}$ ). These findings broadly agree with the ECA, where the RBO asthma group showed significant airflow obstruction and increased BHR at 16 years. Comparing nonwheezers at 18 years in the IOWBC, those subjects with a history of RBO differed significantly from those without RBO only with respect to female sex (fewer females in the RBO group: $38.9 \%$ versus $51.4 \%, \mathrm{p}=0.002$; OR $0.60,95 \%$ CI $0.44-0.83$ ). This may reflect trends for remission of malepredominant early wheeze by young adulthood [6]. They did not differ in terms of lung function at 18 years, which contrasts with the ECA, where lower lung function and higher BHR was found in their RBO remission group at 16 years. At the 10-year follow-up of the IOWBC, we did not find major impairment of lung function in our early transient wheezers, although they did have significantly lower peak expiratory flow in comparison to nonwheezers [2]. Other cohorts have suggested lung function impairments among early transient wheezers more in keeping with the magnitude shown in the ECA [7]. Whether these cohort differences arise from population-related factors is open to speculation.

To further our understanding of these findings we reverted to our prior classification of early-life wheezing as either persistent or early transient wheeze (table 1). Assessing current wheezers at 18 years of age in the IOWBC, $40.2 \%$ were nonwheezers in the first decade of life, $38.3 \%$ early persistent wheezers and $21.5 \%$ early transient wheezers. Prevalence of current wheeze, current asthma, atopy and current smoking at 18 years were significantly elevated in those with persistent wheeze in the first decade of life. They also had significant airflow obstruction along with increased BHR and FeNO at 18 years. Thus, in over half of cases, early persistent wheeze in the first 10 years appeared to track through adolescence and lead into a significant young adult disease state. This indicates strong homology of our early persistent wheezers with the RBO asthma group outlined in the ECA. Indeed, early persistent wheeze comprised $64 \%$ of RBO wheeze at

TABLE 1 18-year outcomes of early-life wheeze phenotypes in the Isle of Wight Birth Cohort

\begin{tabular}{|c|c|c|c|}
\hline & Nonwheeze & Early transient wheeze & Early persistent wheeze \\
\hline Wheeze ever at 18 years & $132 / 567$ (23.3) & $83 / 197(42.1)$ & $94 / 111(84.7)^{* * *}$ \\
\hline Current wheeze at 18 years & $67 / 573(11.7)$ & $36 / 200(18.0)^{\#}$ & $64 / 111(57.7)^{* * *}$ \\
\hline Current asthma at 18 years & $37 / 564(6.6)$ & $24 / 196(12.2)^{\circ}$ & $64 / 110(58.2)^{* * *}$ \\
\hline Atopy at 18 years & $154 / 416(37.0)$ & $47 / 136(34.6)$ & $49 / 79(62.0)^{* * *}$ \\
\hline Current smoker at 18 years & $136 / 566(24.0)$ & $48 / 195(24.6)$ & $48 / 108(44.4)^{* * *}$ \\
\hline FEV $1 / F V C$ at 18 years & $0.88 \pm 0.00$ & $0.88 \pm 0.01$ & $0.82 \pm 0.01 * * *$ \\
\hline FEF $25-75 \%$ at 18 years L. s $^{-1}$ & $4.55 \pm 0.05$ & $4.53 \pm 0.10$ & $3.87 \pm 0.14^{* * *}$ \\
\hline DRS BHR at 18 years & $1.07 \pm 0.02$ & $1.07 \pm 0.02$ & $1.31 \pm 0.05^{* * *}$ \\
\hline $\log _{10} F e n O$ at 18 years ppb & $1.25 \pm 0.02$ & $1.23 \pm 0.03$ & $1.53 \pm 0.06^{* * *}$ \\
\hline \multicolumn{4}{|c|}{ 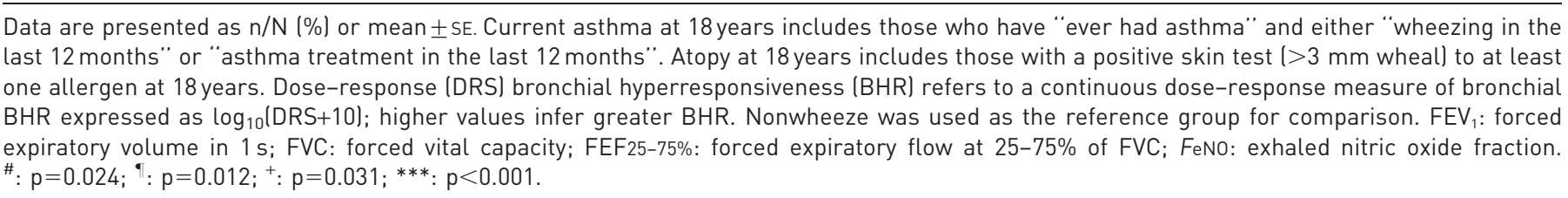 } \\
\hline
\end{tabular}


18 years in the IOWBC. Early transient wheezers appeared to have outgrown their disease at 10 years in the IOWBC. They constituted the vast majority $(77.7 \%)$ of RBO remission at 18 years in the IOWBC. However, at 18 years, almost one fifth of early transient wheezers manifested current wheeze. Furthermore, at 18 years of age, when compared to nonwheezers in early life, they showed elevated prevalence of current wheeze and asthma but no reduction in lung function, and comparable BHR and atopy at that age. Why do some early transient wheezers still express symptoms but no lung function abnormality at 18 years? We recently demonstrated presence of a smoking associated bronchitis at 18 years (undiagnosed wheeze) which showed few hallmarks of asthma in the IOWBC [8]. While that might be a plausible explanation, the early transient wheezers in our study did not actually show elevated smoking prevalence at 18 years of age. Could they be manifesting virus-associated wheeze at 18 years as an alternative explanation? A clearer understanding of what leads to relapse of early transient wheeze is needed and that would be a fruitful area for future research to assess.

In conclusion, while using different methodological approaches based on asthma and wheeze plus different timespans for early life-wheezing, both the ECA and IOWBC studies appear to indicate a broadly similar message. This is that a substantial proportion of early-life asthma or wheeze is associated with respiratory disease in adolescence or young adulthood. Our further findings suggest that a considerable proportion of $\mathrm{RBO}$ asthma in young adulthood is drawn from the early persistent wheeze phenotype, which is potentially identifiable at an early stage $[4,9,10]$. Such individuals appear to have more significant airway disease at 18 years of age. Our findings indicate that the majority of early-life wheezers who lose their disease do so between the ages of 4 and 10 years. However, they indicate a relapsing nature in almost a fifth of early transient wheeze by early adulthood; in other words, "it doesn't all go away". Finally, if an individual does not manifest wheeze in the first 4 years of life, the likelihood of young adult wheeze appears very low. Therefore, as with many things in life, these studies suggest that when it comes to airway disease, the child may indeed be "father of the Man" [11].

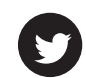

@ERSpublications

When it comes to airway disease, the child may indeed be "father of the Man" http://ow.ly/pWMQ5

Ramesh J. Kurukulaaratchy ${ }^{1,2}$, Sian Evans ${ }^{1,2}$ and S. Hasan Arshad ${ }^{1,2}$

${ }^{1}$ The David Hide Asthma and Allergy Research Centre, St Mary's Hospital, Newport, and ${ }^{2}$ Infection, Inflammation and Immunity Division, University of Southampton Faculty of Medicine, Southampton, UK.

Correspondence: S.H. Arshad, The David Hide Asthma and Allergy Research Centre, St Mary's Hospital, Newport, Isle of Wight, PO30 5TG, UK. E-mail: sha@soton.ac.uk

Received: Apr 302013 | Accepted: May 292013

Conflict of interest: None declared.

\section{References}

1 Hovland V, Riiser A, Mowinckel P, et al. The significance of early recurrent wheeze for asthma outcomes in late childhood. Eur Respir J 2013; 41: 838-845.

2 Kurukulaaratchy RJ, Fenn MH, Waterhouse LM, et al. Characterization of wheezing phenotypes in the first 10 years of life. Clin Exp Allergy 2003; 33: 573-578.

3 Kurukulaaratchy RJ, Matthews S, Arshad SH. Does environment mediate earlier onset of the persistent childhood asthma phenotype? Pediatrics 2004; 113: 345-350.

4 Kurukulaaratchy RJ, Matthews S, Holgate ST, et al. Predicting persistent disease among children who wheeze during early life. Eur Respir J 2003; 22: 767-771.

5 Kurukulaaratchy RJ, Matthews SM, Arshad SH. The natural history of fatal childhood asthma-a case from the Isle of Wight Birth Cohort. J Asthma 2008; 45: 944-947.

6 Almqvist C, Worm M, Leynaert B. Impact of gender on asthma in childhood and adolescence: a GA ${ }^{2}$ LEN review. Allergy 2008; 63: 47-57.

7 Martinez FD, Wright AL, Taussig LM, et al. Asthma and wheezing in the first six years of life. The Group Health Medical Associates. N Engl J Med 1995; 332: 133-138.

8 Raza A, Kurukulaaratchy RJ, Grundy JD, et al. What does adolescent undiagnosed wheeze represent? Findings from the Isle of Wight Cohort. Eur Respir J 2012; 40: 580-588.

9 Matricardi PM, Illi S, Keil T, et al. Predicting persistence of wheezing: one algorithm does not fit all. Eur Respir J 2010; 35: 701-703.

10 Devulapalli CS, Carlsen KCL, Haland G, et al. Severity of obstructive airways disease by age 2 years predicts asthma at 10 years of age. Thorax 2008; 63: 8-13.

11 Wordsworth W. "My heart leaps up when I behold", line 7. Poems, in Two Volumes, vol. 1. London, Longman, Hurst, Rees and Orme, 1807. 